Article

\title{
Evaluation of 99 Pesticide Residues in Major Agricultural Products from the Western Highlands Zone of Cameroon Using QuEChERS Method Extraction and LC-MS/MS and GC-ECD Analyses
}

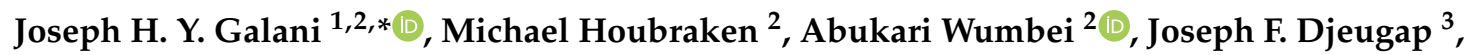 \\ Daniel Fotio $^{4}$ and Pieter Spanoghe ${ }^{2}$ \\ 1 Department of Agriculture and Veterinary Medicine, Université des Montagnes, P.O. Box 208, \\ Bangangté, Cameroon \\ 2 Department of Plants and Crops, Faculty of Bioscience Engineering, Ghent University, Coupure Links 653, \\ 9000 Ghent, Belgium; michael.houbraken@ugent.be (M.H.); abukari.wumbei@ugent.be (A.W.); \\ pieter.spanoghe@ugent.be (P.S.) \\ 3 Department of Plant Protection, Faculty of Agronomy and Agricultural Sciences, University of Dschang, \\ P.O. Box 222, Dschang, Cameroon; jdjeugapfovo@yahoo.fr \\ 4 Inter-States Pesticides Committee of Central Africa, P.O. Box 16344, Yaounde, Cameroon; \\ danfotio@yahoo.co.uk \\ * Correspondence: josephgalani@gmail.com or josephhubert.galaniyamdeu@ugent.be; Tel.: +237-674244181
}

Received: 17 October 2018; Accepted: 6 November 2018; Published: 7 November 2018

Abstract: There is no information available on pesticide residue levels in major food commodities harvested in Cameroon, especially from the western highlands region, the food basket of the country. Hence, this study evaluated the residues of 99 pesticides in 72 samples of 12 agricultural products collected in the region, using QuEChERS (Quick, Easy, Cheap, Effective, Rugged, and Safe) method extraction, and analyzed by liquid chromatography tandem mass spectrometry (LC-MS/MS) and gas chromatography with electron capture detection (GC-ECD). This method was suitable for detecting the targeted compounds: For 81 pesticides by LC-MS/MS, the limit of quantification (LOQ) was between 0.0004 and $0.0537 \mathrm{mg} / \mathrm{kg}$; and for 18 halogenated pesticides by GC-ECD, it ranged from 0.0012 to $0.2180 \mathrm{mg} / \mathrm{kg}$. The residues of 62 pesticides, including 12 banned compounds, were found in the samples. Insecticides (39.7\%) were the most prevalent group, with all the samples containing at least one pesticide. Twenty-one pesticides (34.4\%) exceeded their European Union maximum residue limits (MRLs) and 22 pesticides (34.4\%) were found in all 6 sampling locations. Malathion and $p, p^{\prime}$-DDT were the most distributed pesticides, found in almost all the samples and sampling sites. Food items with the highest rates of positive results were chili pepper (23.2\%), white pepper $(20.2 \%)$, kidney beans (17.3\%), and soybeans (17.2\%). Samples with residues above their MRLs represented $38 \%$ of all the positive analyses; chili pepper (6.4\%) and kidney beans (5.5\%) were found to have the most residues above their MRLs. The most critical food commodities were kidney beans, soybeans, chili pepper, and maize. This data presents scientific evidence that investigation into continuous monitoring and good regulation of pesticide usage in Cameroon is needed, and paves the way for health risks analysis.

Keywords: food safety; pesticide residues; QuEChERS method; staple food; Cameroon

\section{Introduction}

To protect crops against pests and pathogens, over a thousand crop protection products from a broad range of classes are widely used worldwide in various combinations, at different stages 
of cultivation, and during postharvest storage. However, besides the unwanted side effects on the environment, direct toxicity to users, and development of resistance by pathogens and pests associated to the use of certain pesticides, pesticide residues that remain in the food supply could pose a risk for human health because of their potential sub-acute and chronic toxicity [1]. Pesticide residues can be found in different food items, such as dairy products, cereals, fruits, vegetables, and cash crops, and obsolete pesticides have been documented as one of the major problems in Africa [2].

In Cameroon, pesticides are largely used by farmers and traders to protect their growing plants and products in the field and during storage [3-7]. Despite the numerous advantages of pesticide use in agriculture, there is a need for scientific evaluation and control of these products. It is known that pesticide residues can be found in all environmental compartments, but the highest risk for consumers is through consumption of residues in food [8]. In developing countries like Cameroon, there is an increased concern in the dietary risk linked to increased use of crop protection products. However, only minimal emphasis have been put on assessing how the growing use of pesticides can impact food safety. Ten years ago, Gimou et al. [9] revealed low dietary exposure to pesticide residues in the capital city, Yaoundé. But more recently it was found that 75\% of maize, cowpea, and millet samples from northern Cameroon contained pesticide residues above the maximum residue limits (MRLs) [10], and high amounts of organophosphorous pesticide residues were found in stored cowpea and two by-products [5], revealing a potential human dietary risk related to consumption of these grains.

Other information demonstrates a high possible exposure of consumers due to intensive utilization and limited knowledge about pesticide use in the country. Recent studies [4] suggested that the male farmers of Djutitsa in West Cameroon are exposed to agro-pesticides due to improper personal protective equipment (PPE), and this exposure may impair their reproductive function. Inappropriate use of pesticides by Cameroonian farmers has been documented in many studies from different parts of the country $[4,7,10-13]$. This was because farmers did not receive sufficient training on pesticide application and proper assistance from agricultural extension agents [7], which could result in high levels of pesticide residues in local foods. In December 2016, the Cameroon Government prohibited the importation, commercialization, and use of metalaxyl-based pesticides, which were intensively used in cocoa to control black pod disease. This measure was justified by the rejection of Cameroonian cocoa on the international market, due to the presence of metalaxyl residues beyond the $0.1 \mathrm{mg} / \mathrm{kg}$ MRL [14] in cocoa beans originating from Cameroon [15]. Additionally, a high number and various types of obsolete pesticides accumulated over the years were found in the country [16], and because of limited control of pesticide usage, they could be a source of severe acute or chronic pollution [9]. Due to their cheap price on the black market and limited control measures, they can be illegally used on crops and produce [17].

The most common food items produced in Cameroon include cocoa, coffee, palm oil, maize, beans, cassava, groundnuts, plantains, and bananas. Other items like soybeans, chili pepper, Egusi seeds, white pepper, and Bambara nuts largely produced and consumed in Cameroon are also found in markets of neighboring countries, which mostly depend on Cameroon for their food supply. The western highlands of Cameroon, from where the vast majority of these agricultural products originate, is considered as the food basket of the country, and by extension, of the whole Central African region [18]. There is no study investigating pesticide contamination levels of agricultural products from this high production region of Cameroon, hence this work was planned.

Among the various methods of pesticide residue determination in food items, the QuEChERS method (Quick, Easy, Cheap, Effective, Rugged, and Safe) with a dispersive solid-phase extraction (d-SPE) clean-up has been documented to give a better recovery compared to classical techniques. The QuEChERS method has the advantages of high recovery, high sample throughput, low solvent and glassware usage, less labor and bench space, lower reagent costs, ruggedness, and low worker exposure $[19,20]$. Thus, analytical chemists now prefer to use the QuEChERS method with a d-SPE clean-up when required; it is streamlined and effective for analysis of diverse residues in food matrices $[2,21,22]$. The present study analyzes and validates the residues of 99 pesticides in 
72 samples of 12 agricultural products collected in the western highlands of Cameroon, using the QuEChERS method as the extraction and clean-up technique, and liquid chromatography tandem mass spectrometry (LC-MS/MS) and gas chromatography with electron capture detection (GC-ECD) for detection.

\section{Materials and Methods}

\subsection{Reagents}

Analytical grade reagents of above 99\% purity were used in the experiments. UPLC-grade acetonitrile and hexane were procured from VWR Chemicals (Leuven, Belgium). Anhydrous magnesium sulphate, disodium hydrogen sesquihydrate, trisodium citrate dehydrate, sodium chloride, and the pesticide active ingredient standards were purchased from Sigma-Aldrich (Bornem, Belgium). Fifteen-milliliter d-SPE tubes were obtained from Waters (Zellik, Belgium). Water was produced locally though a Milli-Q purification system.

\subsection{Samples Collection}

A total of 72 dried samples were collected in March 2017 from local markets of 6 major towns in the West Region of Cameroon: Bafang, Bangangté, Bafoussam, Dschang, Foumban, and Mbouda (Figure 1). They belonged to 12 agricultural products; namely, 8 groundnut samples, 6 soybean, 10 kidney bean, 6 black bean, 7 cowpea, 6 chili pepper, 7 Egusi seeds, 4 coffee beans, 2 cocoa beans, 11 maize, 2 white pepper, and 3 Bambara nuts. Interviews of the wholesalers during sample collection revealed that each food batch was made of a pool of small lots originating from different farmers of the neighboring villages. Therefore, they were considered as representative samples. Approximately $200 \mathrm{~g}$ of each sample was collected in a hard paper envelope within polyethylene plastic bag, sealed, labelled, transported to the Laboratory of Crop Protection Chemistry at Ghent University, Belgium, and kept at $20^{\circ} \mathrm{C}$ until extraction and analysis.

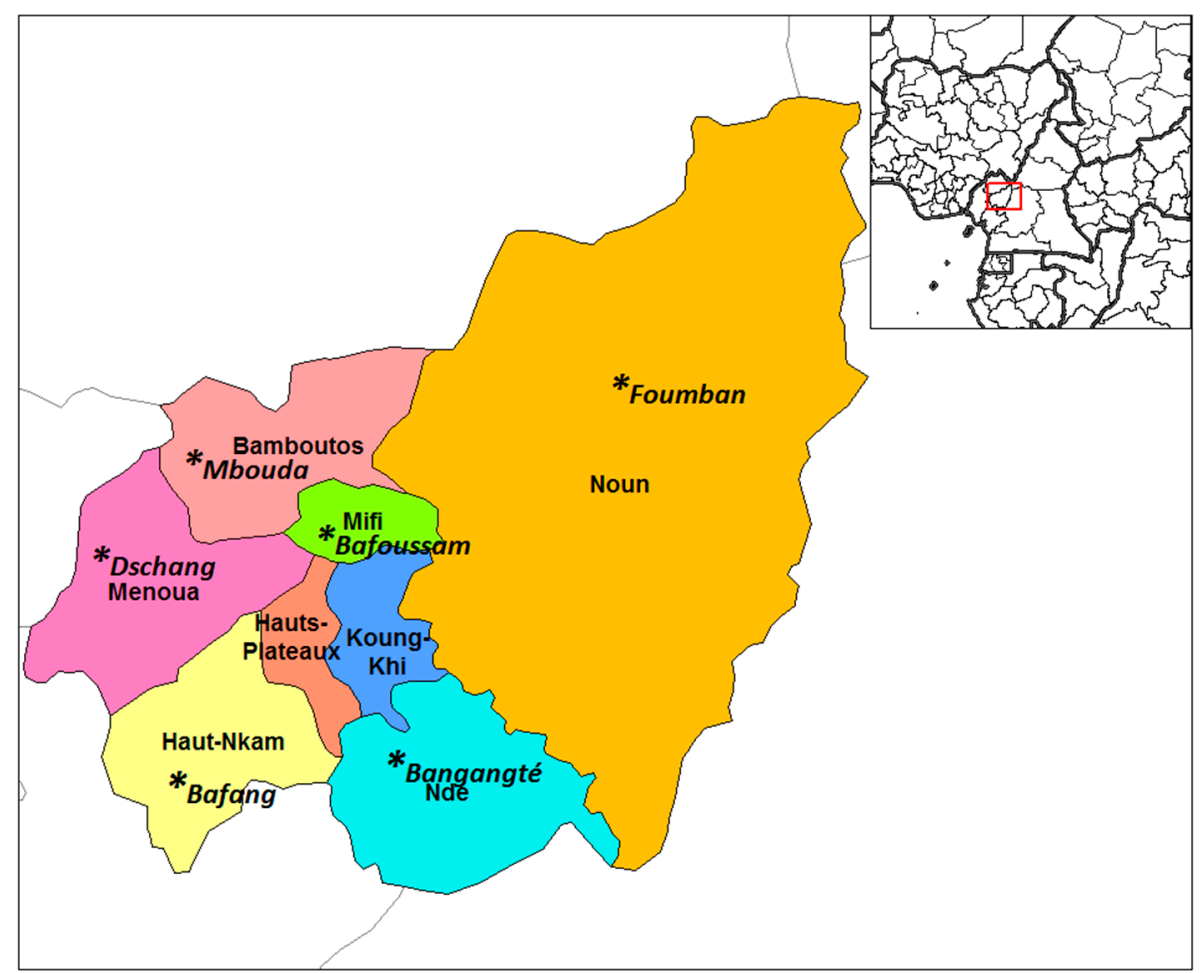

Figure 1. Map of the West Region of Cameroon showing the administrative divisions and major towns where samples were collected. 


\subsection{Pesticides Extraction}

Extraction and clean-up were performed using the QuEChERS method commonly used in the multi-residue analysis of food matrices. Each sample (approx. $50 \mathrm{~g}$ ) was ground to powder using a household mill equipped with a stainless steel knife (Krups, Fleurus, Belgium). Each time the grinder was thoroughly washed to avoid cross-contamination between samples. Precisely $5 \mathrm{~g}$ of powder was weighed into a $50 \mathrm{~mL}$ Teflon capped centrifuge tube, $5 \mathrm{~mL}$ of Milli-Q water followed by $15 \mathrm{~mL}$ of acetonitrile was added, and the mixture was vigorously shaken for $1 \mathrm{~min}$. A mixture of disodium hydrogen citrate sesquihydrate $(0.75 \mathrm{~g})$, trisodium citrate dihydrate $(1.5 \mathrm{~g})$, sodium chloride $(1.5 \mathrm{~g})$, and anhydrous magnesium sulphate $(6 \mathrm{~g})$ was added to the extract in the tube, which was agitated for $3 \mathrm{~min}$ at $300 \mathrm{rpm}$ on a shaker (Edmund Bühler, Hechingen, Germany). The sample was centrifuged for $5 \mathrm{~min}$ at 10,000 rpm (Eppendorf, Leipzig, Germany) and the supernatant was collected. Samples of groundnuts, chili pepper, coffee, cocoa, and white pepper required clean-up to remove any organic acids, polar pigments, and other compounds that could interfere with the analysis. For clean-up, $8 \mathrm{~mL}$ of the supernatant was pipetted into a $15 \mathrm{~mL}$ d-SPE tube packed with $300 \mathrm{mg}$ primary secondary amines (PSA), $900 \mathrm{mg} \mathrm{MgSO}$, and $150 \mathrm{mg}$ octadecyl (C18). The content of the tube was then shaken for $1 \mathrm{~min}$, centrifuged for $5 \mathrm{~min}$ at $3000 \mathrm{rpm}$, and the supernatant collected. For LC-MS/MS analysis, $1 \mathrm{~mL}$ of the supernatant was transferred into a $10 \mathrm{~mL}$ flask and the volume was made up to $10 \mathrm{~mL}$ with Milli-Q water. After mixing, $2 \mathrm{~mL}$ of the diluted solution was sampled into a screw cap autosampler vial for chromatography analysis. For GC-ECD analysis, $5 \mathrm{~mL}$ of supernatant was taken into a $10 \mathrm{~mL}$ flask and acetonitrile was evaporated (Heidolph Instruments, Schwabach, Germany) at $40{ }^{\circ} \mathrm{C}$ until dryness. Acetonitrile was replaced by $5 \mathrm{~mL}$ of hexane, and $2 \mathrm{~mL}$ of the extract was sampled into a crimp top autosampler vial for analysis.

\subsection{Sample Analysis}

The selection of potential active ingredients to be screened was based on the list of registered agricultural pesticides authorized in Cameroon by the Ministry of Agriculture and Rural Development, commonly used on the sample crops [23]. For different chemical classes of pesticides, LC-MS/MS and GC-ECD were separately used.

\subsubsection{Liquid Chromatography Tandem Mass Spectrometry}

Eighty-one compounds were analyzed by LC-MS /MS (Table 1) following a protocol adapted from Houbraken et al. [24]. The equipment consisted of a Waters Acquity UPLC module coupled to a Waters Xevo TQD Tandem triple quadrupole mass spectrometer equipped with an electrospray ionization (ESI) interface (Waters, Zellik, Belgium). Separation was carried out through a HSS T3 column (100 mm $\times 2.1 \mathrm{~mm}, 1.8 \mu \mathrm{m}$ ) maintained at $40^{\circ} \mathrm{C}$. The injection volume was $10 \mu \mathrm{L}$, and mobile phase A consisted of $10 \mathrm{mM}$ ammonium acetate solution in water, while mobile phase B was acetonitrile with $0.1 \%$ formic acid. The flow rate was set at $0.4 \mathrm{~mL} / \mathrm{min}$ with a run time of $10 \mathrm{~min}$. The separation started with an initial gradient of $98 \%$ mobile phase A for $0.25 \mathrm{~min}$, followed by a linear gradient to $98 \%$ mobile phase B from 0.25 to $7 \mathrm{~min}$, which was maintained for $1 \mathrm{~min}$. Then, a linear gradient was used to $98 \%$ mobile phase A and the column was reconditioned for $1 \mathrm{~min}$. Except for fludioxonil and 2,4-dichlorophenoxyacetic acid (2,4-D), which were analyzed in negative ion mode, analyses of all the other pesticides were performed in positive ion mode. The ESI capillary needle was maintained at $+2 \mathrm{kV}$, the source temperature at $150{ }^{\circ} \mathrm{C}$, the desolvation temperature at $600{ }^{\circ} \mathrm{C}$, cone gas flow at $50 \mathrm{~L} / \mathrm{h}$, and desolvation gas flow at $1000 \mathrm{~L} / \mathrm{h}$. The analytes were monitored and quantified using multiple reaction monitoring (MRM). Optimization of the MS/MS conditions, identification of the parent and product ions, as well as the selection of the cone and collision voltages, were performed with direct infusion of their individual standard solutions prepared at $1 \mathrm{mg} / \mathrm{mL}$ in acetonitrile/water (10/90). Two different $m / z$ transitions were selected for each analyte, one for quantification (QIT) and one for 
confirmation (CIT). The dwell time was calculated automatically. MassLynx 4.1 software (Waters) was used for the LC-MS/MS system control and data acquisition and analysis.

\subsubsection{Gas Liquid Chromatography with Electron Capture Detection}

Eighteen halogenated compounds (Table 2) were analyzed using an Agilent 6890N Network gas chromatograph with an auto-sampler, coupled to an electron capture detector (Agilent Technologies, Diegem, Belgium). The protocol was adapted from Amulen et al. [25]. Separation was performed on a HP-5MS (5\% phenyl methyl siloxane) capillary column $(30 \mathrm{~m} \times 0.25 \mathrm{~mm}, 0.25 \mu \mathrm{m})$. The operating conditions were as follows: The column was initially set at a temperature of $80^{\circ} \mathrm{C}$, then increased at a rate of $30{ }^{\circ} \mathrm{C} / \mathrm{min}$ to $205^{\circ} \mathrm{C}$ and held for $4 \mathrm{~min}$. It was further increased at a rate of $20{ }^{\circ} \mathrm{C} / \mathrm{min}$ to $290{ }^{\circ} \mathrm{C}$ and held constant for $8 \mathrm{~min}$, followed by an increase at a rate of $50^{\circ} \mathrm{C} / \mathrm{min}$ to $325^{\circ} \mathrm{C}$. The temperature of the injector and detector were maintained at $280^{\circ} \mathrm{C}$ and $300{ }^{\circ} \mathrm{C}$, respectively. Helium was used as a carrier gas at a flow rate of $1.1 \mathrm{~mL} / \mathrm{min}$, and the injections were made in the split mode with a split ratio of 52.7:1. The Agilent GC ChemStation version Rev. A.10.02 software was used for system control and data acquisition and analysis.

\subsection{Method Validation}

Validation of the analysis was performed as recommended in Document No. SANTE/11945/2015 [26]. The validation parameters were linearity, limit of detection (LOD), limit of quantification (LOQ), accuracy, and precision. Eight replicates of samples obtained from organic agriculture markets in Belgium were spiked at $0.01 \mathrm{mg} / \mathrm{kg}$ with pesticide standards. The spiked samples were left for $1 \mathrm{~h}$ to allow pesticide absorption into samples before being subjected to the extraction, clean-up process, and analysis as described previously. The LOD together with the LOQ were calculated by multiplying the standard deviation of the detected pesticide concentrations from the replicates by 2.99 and 10, respectively. The accuracy (average recovery) was calculated by dividing the recovered concentrations by spiked concentration, and precision (relative standard deviation of within-laboratory reproducibility analyses, \%RSD) was obtained by dividing the standard deviation by the average concentration. To determine linearity and calculate pesticide content in samples, five different concentrations of the pesticide standards stock solution $(0.1,0.05,0.01,0.005$, $0.001 \mathrm{mg} / \mathrm{L}$ ) were prepared by dilution with acetonitrile/water (10/90) to make a calibration curve.

\subsection{Data Analysis}

Descriptive statistics depicting the frequencies of occurrence and the distribution of quantified pesticides in the analyzed agricultural products and the sampling locations were generated. The quantified pesticides were compared with the maximum residue limits (MRLs) of the European Union regulations. As the number of samples was not equal for all the food items, the contamination rate (the relative number of positive samples), the pesticide rate (relative number of pesticides quantified), as well as the above MRLs rate (relative number of samples above the MRLs values) for each food item were calculated.

\section{Results}

\subsection{Method Validation}

Five attributes of the extraction and analysis methods were validated: Accuracy (percentage recovery), precision (\%RSD), limit of detection (LOD), limit of quantification (LOQ), and linearity. The obtained recoveries data and validation parameters of the 2 analysis methods are presented in Supplementary Material Table S1. The linearity of analysis of 81 pesticides by LC-MS/MS ranged between 0.9993 and 0.9999 (Table 1). The recovery varied greatly among the pesticides, and for a given pesticide, among the food commodities, with the median between $11.5 \%$ and $227 \%$ for methsulfuron-methyl and spiroxamine, respectively. In general, high recoveries $(>120)$ were mostly 
found in groundnuts, soybeans, beans, and cocoa, while low values $(<70)$ were mostly obtained in maize, white pepper, Egusi seeds, and coffee. The \%RSD showed consistent precision with only 30 out of $720(4.1 \%)$ of the \%RSD values above the $20 \%$ acceptable threshold. The LOD ranged between 0.0001 and $0.0161 \mathrm{mg} / \mathrm{kg}$, and the LOQ between 0.0004 and $0.0537 \mathrm{mg} / \mathrm{kg}$. 
Table 1. Parameters of acquisition method and linearity results of LC-MS/MS analysis of 81 pesticides.

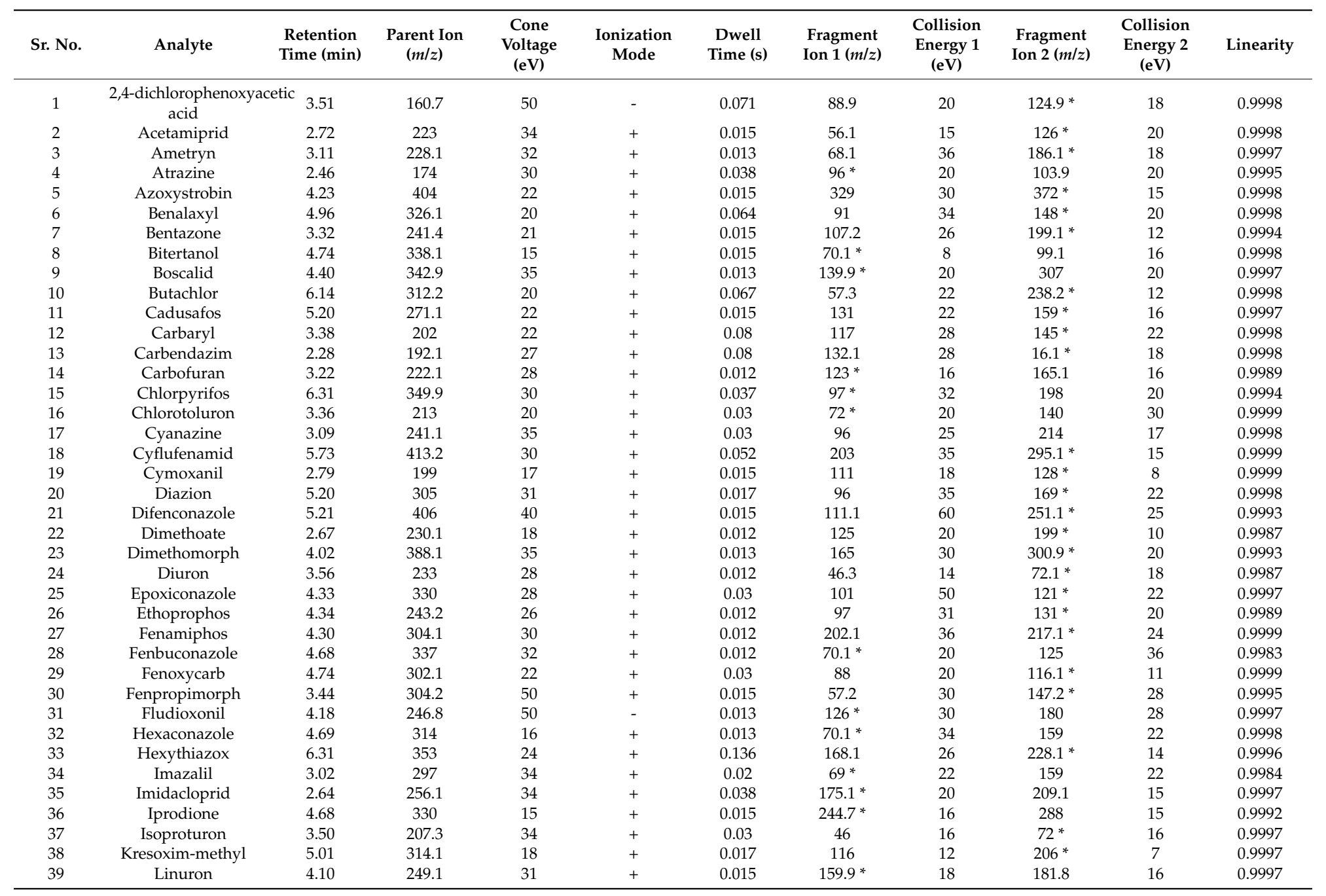


Table 1. Cont

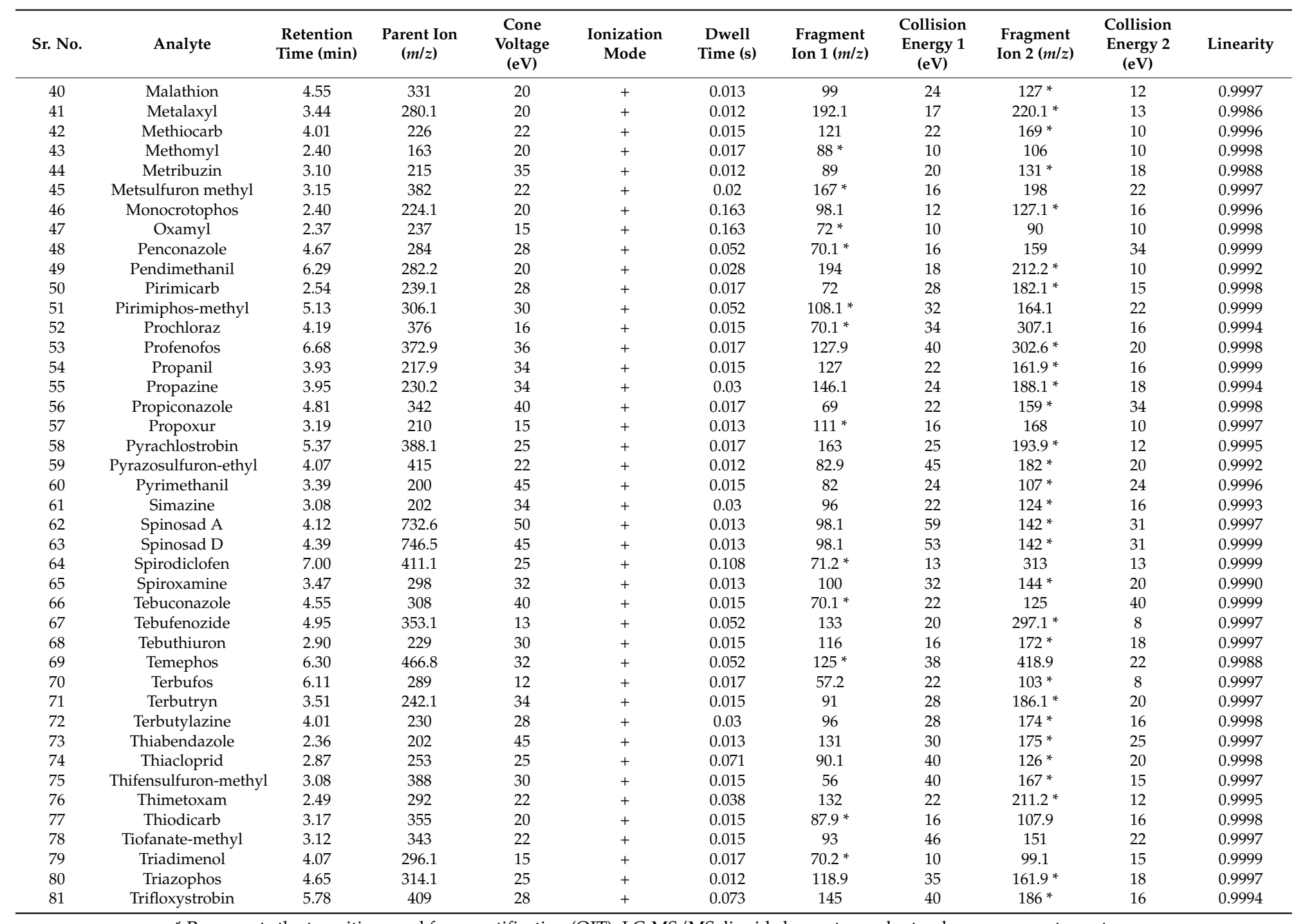

${ }^{*}$ Represents the transition used for quantification (QIT). LC-MS/MS: liquid chromatography tandem mass spectrometry. 
Analysis of 18 halogenated pesticides by GC-ECD showed linearity between 0.9987 and 0.9999 (Table 2). Large variations were also observed in recoveries, with median values that ranged between 87.8 and $170.8 \%$ for Aldrin and $o, p^{\prime}$-DDT, respectively. In general, beans and cocoa showed high recovery values, while low values were found in groundnuts and chili pepper. The \%RSD showed that the analyses were precise; only 3 out of $153(1.9 \%)$ of the $\%$ RSD values were above the $20 \%$ limit. The LOD varied from 0.0004 to $0.0652 \mathrm{mg} / \mathrm{kg}$, and the LOQ from 0.0012 to $0.2180 \mathrm{mg} / \mathrm{kg}$.

Table 2. Parameters and linearity results of GC-ECD analysis of 18 pesticides.

\begin{tabular}{cccc}
\hline Sr. No. & Retention Time (min) & Analyte & Linearity \\
\hline 1 & 10.6 & Heptaclor & 0.9997 \\
2 & 10.8 & $\beta$-HCH & 0.9996 \\
3 & 11.4 & Chlorothalonil & 0.9992 \\
4 & 12.05 & Alachlor & 0.9994 \\
5 & 12.8 & Aldrin & 0.9993 \\
6 & 13.5 & Hexachlorobenzene & 0.9999 \\
7 & 13.6 & Captan & 0.9987 \\
8 & 14.2 & $\alpha$-Endosulfan & 0.9999 \\
9 & 14.5 & $p, p^{\prime}$-DDE & 0.9999 \\
10 & 14.7 & Dieldrin & 0.9999 \\
11 & 15.2 & Endrin & 0.9996 \\
12 & 15.3 & $p, p^{\prime}$-DDD & 0.9998 \\
13 & 15.3 & $\beta$-Endosulfan & 0.9998 \\
14 & 15.5 & $o, p^{\prime}$-DDT & 0.9999 \\
15 & 16.2 & $p, p^{\prime}$-DDT & 0.9997 \\
16 & 17.4 & Bifenthrin & 0.9999 \\
17 & 17.6 & Methoxychlor & 0.9988 \\
18 & 24.2 & Cypermethrin & 0.9999
\end{tabular}

$\mathrm{HCH}=$ Hexachlorocyclohexane, DEE = Dichlorodiphenyldichloroethylene, DDD = Dichlorodiphenyldichloroethane, DDT $=$ Dichlorodiphenyltrichloroethane.

\subsection{Pesticide Residues in Food Samples}

After validation of the QuEChERS method, 99 pesticide residues were screened in 72 samples of 12 agricultural products. The results of the quantified pesticides are available in Supplementary Material Table S2, and the pesticide distributions are summarized in Table 3. All of the 18 halogenated compounds analyzed by GC-ECD could be quantified in the samples, against 44 of the 81 compounds analyzed by LC-MS/MS. Residues of 62 pesticides were found in the samples: $39.7 \%$ were insecticides, $30.9 \%$ were fungicides, herbicides represented $16.2 \%$, acaricides $8.8 \%$, and nematicides $4.4 \%$. Twelve banned compounds were found in the samples, among which there was 1 herbicide (alachlor), 3 insecticide/acaricides (malathion, $\alpha$-Endosulfan, and $\beta$-Endosulfan), and 8 insecticides $(\beta-\mathrm{HCH}$, aldrin, carbaryl, carbofuran, diazinon, dieldrin, heptachlor, and propoxur).

The distribution of the pesticides by sampling location showed that 22 pesticides (34.4\%) were found in all 6 locations, while 15 pesticides $(24.2 \%)$ could be found at only one sampling site. The repartition based on food commodities showed that 12 compounds, representing $19.3 \%$ of the pesticides quantified in the samples, were found in all 12 food items; except for malathion, 11 of them are halogenated compounds. However, 17 compounds (27.7\%) could be quantified in only 1 food commodity. Considering individual pesticides, malathion was the most distributed pesticide as it was found in 70 samples, followed by $p, p^{\prime}$-DDT, which was quantified in 69 samples. Thirteen individual halogenated pesticides were found in above 40 samples. Fifteen pesticides were quantified in only 1 sample. Concentration-wise, the single pesticides with the highest quantified concentrations were malathion in kidney beans $(5.5 \mathrm{mg} / \mathrm{kg})$, hexachlorobenzene in kidney beans $(3.1 \mathrm{mg} / \mathrm{kg})$, chlorotoluron in soybeans $(1.5 \mathrm{mg} / \mathrm{kg})$, cypermethrin in kidney beans $(0.9 \mathrm{mg} / \mathrm{kg})$, captan in chili pepper $(0.8 \mathrm{mg} / \mathrm{kg})$, and methoxychlor in maize $(0.8 \mathrm{mg} / \mathrm{kg})$. In general, malathion was found at all 12 sampling locations, in almost all the 72 samples, in all 12 food commodities, and with the highest concentrations. Whereas 
isoproturon was found at only 1 sampling location, in a single black bean sample, and with the lowest concentration $(0.0004 \mathrm{mg} / \mathrm{kg})$.

The distribution of quantified pesticides in the 12 food items (Table 4) demonstrates that all samples contained one or more of the 62 quantified pesticides. Chili pepper showed the highest relative number of positive samples, with a contamination rate of $23.2 \%$, followed by white pepper $(20.2 \%)$, kidney beans $(17.3 \%)$, and soybeans (17.2\%). White pepper, with a pesticide rate of $14.6 \%$, contained the highest relative number of pesticides per sample, followed by cocoa $(8.1 \%)$ and Bambara nuts $(8.1 \%)$.

In total, 21 pesticides (34.4\%) were found above their existing European Union MRL values (Supplementary Material Table S2, Table 3). Malathion was found above its MRL in 49 samples, followed by aldrin (30 samples), hexachlorobenzene ( 25 samples), alachlor (22 samples), and $\beta-\mathrm{HCH}$ (21 samples). Except for Bambara nuts and Egusi seeds, which do not have established MRL values yet, all the food items had residues above the threshold limit fixed by the European Union. Samples with residues above MRLs represented 38\% of all the positive analyses, and were found in all 6 sampling locations. Chili pepper showed the highest above MRL rate $(6.4 \%)$, followed by kidney beans $(5.5 \%)$, while the lowest rate $(2.1 \%)$ was found in groundnuts. 
Table 3. Characteristics of the 62 pesticides analyzed by LC-MS/MS and GC-ECD (gas chromatography-electron capture detection) in 12 food items from the western highlands of Cameroon.

\begin{tabular}{|c|c|c|c|c|c|c|c|c|c|c|c|c|}
\hline Sr. No. & Pesticide & Method & Application & Banned & $\begin{array}{c}\text { Number } \\
\text { of } \\
\text { Positive } \\
\text { Locations }\end{array}$ & $\begin{array}{l}\text { Number of } \\
\text { Positive } \\
\text { Food } \\
\text { Items }\end{array}$ & $\begin{array}{l}\text { Number of } \\
\text { Positive } \\
\text { Samples }\end{array}$ & $\begin{array}{l}\text { Lowest Value } \\
(\mathrm{mg} / \mathrm{kg})\end{array}$ & $\begin{array}{l}\text { 1eHighest Val } \\
\text { (mg/kg) }\end{array}$ & $\begin{array}{l}\text { uMean Value } \\
\text { (mg/kg) }\end{array}$ & $\begin{array}{l}\text { Median } \\
(\mathrm{mg} / \mathrm{kg})\end{array}$ & $\begin{array}{l}\text { Number of } \\
\text { Samples } \\
\text { >MRLs }\end{array}$ \\
\hline 1 & Acetamiprid & LC-MS/MS & Insecticide & No & 5 & 4 & 6 & 0.0004 & 0.0400 & 0.0086 & 0.0025 & 0 \\
\hline 2 & Alachlor & GC-ECD & Herbicide & Yes & 6 & 12 & 48 & 0.0026 & 0.6275 & 0.0610 & 0.0186 & 22 \\
\hline 3 & Aldrin & GC-ECD & Insecticide & Yes & 6 & 12 & 64 & 0.0012 & 0.4646 & 0.0663 & 0.0224 & 30 \\
\hline 4 & Atrazine & LC-MS/MS & Herbicide & No & 6 & 11 & 29 & 0.0006 & 0.0040 & 0.0018 & 0.0013 & 0 \\
\hline 5 & Azoxystrobin & LC-MS/MS & Fungicide & No & 1 & 1 & 1 & 0.0011 & 0.0011 & 0.0011 & 0.0011 & 0 \\
\hline 6 & Benalaxyl & LC-MS/MS & Fungicide & No & 2 & 1 & 2 & 0.0046 & 0.0222 & 0.0134 & 0.0134 & 0 \\
\hline 7 & Bentazon & LC-MS/MS & Herbicide & No & 3 & 4 & 5 & 0.0020 & 0.0128 & 0.0066 & 0.0062 & 0 \\
\hline 8 & Bifenthrin & GC-ECD & Insecticide & No & 2 & 3 & 4 & 0.0056 & 0.0310 & 0.0139 & 0.0096 & 0 \\
\hline 9 & Bitertanol & LC-MS/MS & Fungicide & No & 4 & 3 & 4 & 0.0008 & 0.0093 & 0.0034 & 0.0017 & 0 \\
\hline 10 & Cadusafos & LC-MS/MS & Insecticide/Nematicide & No & 4 & 1 & 4 & 0.0089 & 0.6285 & 0.1684 & 0.0182 & 3 \\
\hline 11 & Captan & GC-ECD & Fungicide & No & 6 & 12 & 60 & 0.0097 & 0.8557 & 0.1467 & 0.0390 & 19 \\
\hline 12 & Carbaryl & LC-MS/MS & Insecticide & Yes & 2 & 2 & 2 & 0.0297 & 0.0758 & 0.0528 & 0.0528 & 0 \\
\hline 13 & Carbendazim & LC-MS/MS & Fungicide & No & 1 & 1 & 1 & 0.0014 & 0.0014 & 0.0014 & 0.0014 & 0 \\
\hline 14 & Carbofuran & LC-MS/MS & Insecticide & Yes & 3 & 2 & 3 & 0.0006 & 0.0027 & 0.0015 & 0.0011 & 0 \\
\hline 15 & Chlorothalonil & GC-ECD & Fungicide & No & 6 & 12 & 48 & 0.0039 & 0.0683 & 0.0123 & 0.0092 & 2 \\
\hline 16 & Chlorpyrifos & LC-MS/MS & Insecticide & No & 3 & 5 & 6 & 0.0071 & 0.3667 & 0.1155 & 0.0720 & 3 \\
\hline 17 & Chlorotoluron & LC-MS/MS & Herbicide & No & 6 & 7 & 11 & 0.0709 & 1.5508 & 0.2609 & 0.1083 & 10 \\
\hline 18 & Cypermethrin & GC-ECD & Insecticide & No & 6 & 12 & 52 & 0.0014 & 0.9449 & 0.0694 & 0.0213 & 11 \\
\hline 19 & Diazinon & LC-MS/MS & Insecticide & Yes & 1 & 1 & 1 & 0.0020 & 0.0020 & 0.0020 & 0.0020 & 0 \\
\hline 20 & Dieldrin & GC-ECD & Insecticide & Yes & 6 & 10 & 44 & 0.0012 & 0.0604 & 0.0069 & 0.0029 & 5 \\
\hline 21 & Difenconazole & LC-MS/MS & Fungicide & No & 6 & 3 & 11 & 0.0009 & 0.0021 & 0.0014 & 0.0013 & 0 \\
\hline 22 & Dimethomorph & LC-MS/MS & Fungicide & No & 1 & 1 & 1 & 0.0007 & 0.0007 & 0.0007 & 0.0007 & 0 \\
\hline 23 & Endrin & GC-ECD & Insecticide & No & 6 & 10 & 36 & 0.0012 & 0.0337 & 0.0050 & 0.0028 & 3 \\
\hline 24 & Epoxiconazole & LC-MS/MS & Fungicide & No & 6 & 6 & 26 & 0.0004 & 0.0176 & 0.0032 & 0.0016 & 0 \\
\hline 25 & Fenamiphos & LC-MS/MS & Nematicide & No & 1 & 1 & 1 & 0.0014 & 0.0014 & 0.0014 & 0.0014 & 0 \\
\hline 26 & Fenbuconazole & LC-MS/MS & Fungicide & No & 3 & 2 & 3 & 0.0009 & 0.0015 & 0.0011 & 0.0009 & 0 \\
\hline 27 & Fenoxycarb & LC-MS/MS & Insecticide & No & 1 & 1 & 1 & 0.0013 & 0.0013 & 0.0013 & 0.0013 & 0 \\
\hline 28 & Fenpropimorf & LC-MS/MS & Fungicide & No & 4 & 3 & 7 & 0.0004 & 0.0013 & 0.0008 & 0.0005 & 0 \\
\hline 29 & Heptaclor & GC-ECD & Insecticide & Yes & 6 & 7 & 16 & 0.0012 & 0.1236 & 0.0182 & 0.0021 & 2 \\
\hline 30 & Hexachlorobenzene & GC-ECD & Fungicide & No & 6 & 12 & 57 & 0.0014 & 3.0895 & 0.1362 & 0.0219 & 25 \\
\hline 31 & Hexaconazole & LC-MS/MS & Fungicide & No & 2 & 2 & 2 & 0.0025 & 0.0121 & 0.0073 & 0.0073 & 0 \\
\hline 32 & Imazalil & LC-MS/MS & Fungicide & No & 1 & 1 & 1 & 0.0032 & 0.0032 & 0.0032 & 0.0032 & 0 \\
\hline 33 & Imidacloprid & LC-MS/MS & Insecticide & No & 2 & 5 & 6 & 0.0008 & 0.0120 & 0.0045 & 0.0035 & 0 \\
\hline 34 & Isoproturon & LC-MS/MS & Herbicide & No & 1 & 1 & 1 & 0.0004 & 0.0004 & 0.0004 & 0.0004 & 0 \\
\hline 35 & Linuron & LC-MS/MS & Herbicide & No & 2 & 3 & 3 & 0.0024 & 0.1041 & 0.0367 & 0.0036 & 1 \\
\hline 36 & Malathion & LC-MS/MS & Insecticide/Acaricide & Yes & 6 & 12 & 70 & 0.0073 & 5.5269 & 0.9546 & 0.3137 & 49 \\
\hline
\end{tabular}


Table 3. Cont.

\begin{tabular}{|c|c|c|c|c|c|c|c|c|c|c|c|c|}
\hline Sr. No. & Pesticide & Method & Application & Banned & $\begin{array}{c}\text { Number } \\
\text { of } \\
\text { Positive } \\
\text { Locations }\end{array}$ & $\begin{array}{c}\text { Number of } \\
\text { Positive } \\
\text { Food } \\
\text { Items } \\
\end{array}$ & $\begin{array}{l}\text { Number of } \\
\text { Positive } \\
\text { Samples }\end{array}$ & $\begin{array}{l}\text { Lowest Valuef } \\
(\mathrm{mg} / \mathrm{kg})\end{array}$ & $\begin{array}{l}\text { eHighest }) \\
(\mathrm{mg} / \mathrm{kg})\end{array}$ & $\begin{array}{l}\text { ValuMean Value } \\
(\mathrm{mg} / \mathrm{kg})\end{array}$ & $\begin{array}{l}\text { Median } \\
(\mathrm{mg} / \mathrm{kg})\end{array}$ & $\begin{array}{l}\text { Number of } \\
\text { Samples } \\
\text { >MRLs }\end{array}$ \\
\hline 37 & Metalaxyl & LC-MS/MS & Fungicide & Yes & 5 & 7 & 9 & 0.0004 & 0.1736 & 0.0205 & 0.0007 & 1 \\
\hline 38 & Methiocarb & LC-MS/MS & Acaricide/Insecticide & No & 3 & 2 & 4 & 0.0015 & 0.0061 & 0.0043 & 0.0048 & 6 \\
\hline 39 & Methoxychlor & GC-ECD & Insecticide & No & 5 & 5 & 10 & 0.0160 & 0.8165 & 0.1821 & 0.0475 & 0 \\
\hline 40 & Methribuzin & LC-MS/MS & Herbicide & No & 1 & 1 & 1 & 0.0037 & 0.0037 & 0.0037 & 0.0037 & 0 \\
\hline 41 & Monocrotophos & LC-MS/MS & Acaricide & No & 3 & 3 & 3 & 0.0012 & 0.0079 & 0.0034 & 0.0012 & 0 \\
\hline 42 & $o, p^{\prime}$-DDT & GC-ECD & Insecticide & No & 6 & 10 & 51 & 0.0013 & 0.0156 & 0.0041 & 0.0027 & 0 \\
\hline 43 & $p, p^{\prime}-\mathrm{DDD}$ & GC-ECD & Insecticide & No & 6 & 12 & 42 & 0.0012 & 0.0241 & 0.0037 & 0.0022 & 0 \\
\hline 44 & $p, p^{\prime}$-DDE & GC-ECD & Insecticide & No & 6 & 12 & 44 & 0.0013 & 0.0276 & 0.0051 & 0.0024 & 0 \\
\hline 45 & $p, p^{\prime}$-DDT & GC-ECD & Insecticide & No & 6 & 12 & 69 & 0.0033 & 0.1466 & 0.0246 & 0.0146 & 7 \\
\hline 46 & Penconazole & LC-MS/MS & Fungicide & No & 4 & 2 & 7 & 0.0062 & 0.0214 & 0.0116 & 0.0098 & 0 \\
\hline 47 & Pirimiphos-methyl & LC-MS/MS & Insecticide & No & 6 & 11 & 48 & 0.0004 & 0.2735 & 0.0139 & 0.0030 & 6 \\
\hline 48 & Propazine & LC-MS/MS & Herbicide & No & 1 & 1 & 1 & 0.0032 & 0.0032 & 0.0032 & 0.0032 & 0 \\
\hline 49 & Propiconazole & LC-MS/MS & Fungicide & No & 2 & 2 & 3 & 0.0004 & 0.0032 & 0.0017 & 0.0016 & 0 \\
\hline 50 & Propoxur & LC-MS/MS & Insecticide & Yes & 2 & 2 & 2 & 0.0006 & 0.0017 & 0.0011 & 0.0011 & 0 \\
\hline 51 & Pyrimethanil & LC-MS/MS & Fungicide & No & 2 & 4 & 4 & 0.0062 & 0.0929 & 0.0372 & 0.0248 & 1 \\
\hline 52 & Simazine & LC-MS/MS & Herbicide & No & 1 & 1 & 1 & 0.0005 & 0.0005 & 0.0005 & 0.0005 & 0 \\
\hline 53 & Tebuconazole & LC-MS/MS & Fungicide & No & 1 & 1 & 1 & 0.0016 & 0.0016 & 0.0016 & 0.0016 & 0 \\
\hline 54 & Tebufenozide & LC-MS/MS & Insecticide & No & 5 & 5 & 9 & 0.0004 & 0.0048 & 0.0014 & 0.0007 & 0 \\
\hline 55 & Terbuthryn & LC-MS/MS & Herbicide & No & 1 & 1 & 1 & 0.0041 & 0.0041 & 0.0041 & 0.0041 & 0 \\
\hline 56 & Terbuthylazine & LC-MS/MS & Herbicide & No & 6 & 11 & 41 & 0.0053 & 0.1878 & 0.0454 & 0.0275 & 8 \\
\hline 57 & Thiofanate-methyl & LC-MS/MS & Fungicide & No & 3 & 2 & 3 & 0.0013 & 0.0180 & 0.0070 & 0.0017 & 0 \\
\hline 58 & Triazophos & LC-MS/MS & Acaricide/Nematicide & No & 2 & 2 & 2 & 0.0013 & 0.0020 & 0.0016 & 0.0016 & 0 \\
\hline 59 & Trifloxystrobin & LC-MS/MS & Fungicide & No & 1 & 1 & 1 & 0.0012 & 0.0012 & 0.0012 & 0.0012 & 0 \\
\hline 60 & $\alpha$-Endosulfan & GC-ECD & Insecticide/Acaricide & Yes & 6 & 12 & 63 & 0.0012 & 0.0415 & 0.0076 & 0.0049 & 0 \\
\hline 61 & $\beta$-Endosulfan & GC-ECD & Insecticide/Acaricide & Yes & 1 & 1 & 1 & 0.0017 & 0.0017 & 0.0017 & 0.0017 & 0 \\
\hline 62 & $\beta-\mathrm{HCH}$ & GC-ECD & Insecticide & Yes & 6 & 12 & 47 & 0.0012 & 0.1371 & 0.0153 & 0.0060 & 21 \\
\hline
\end{tabular}


Table 4. Distribution of quantified pesticides in the 12 food items from the western highlands of Cameroon.

\begin{tabular}{|c|c|c|c|c|c|c|c|c|c|}
\hline Sr. No. & Food Item & $\begin{array}{l}\text { Number of } \\
\text { Samples }\end{array}$ & $\begin{array}{l}\text { Number of } \\
\text { Analyses }\end{array}$ & $\begin{array}{c}\text { Number of } \\
\text { Quantifications }\end{array}$ & $\begin{array}{l}\text { Contamination } \\
\text { Rate }(\%)\end{array}$ & $\begin{array}{l}\text { Number of } \\
\text { Pesticides } \\
\text { Quantified }\end{array}$ & $\begin{array}{l}\text { Pesticides } \\
\text { Rate (\%) }\end{array}$ & $\begin{array}{c}\text { Number of } \\
\text { Samples >MRLs }\end{array}$ & $\begin{array}{c}\text { Above MRLs } \\
\text { Rate (\%) }\end{array}$ \\
\hline 1 & Bambara nuts & 3 & 297 & 44 & 14.8 & 24 & 8.1 & NA & NA \\
\hline 2 & Black beans & 6 & 594 & 56 & 9.4 & 22 & 3.7 & 18 & 3.0 \\
\hline 3 & Chili pepper & 6 & 594 & 138 & 23.2 & 35 & 5.9 & 38 & 6.4 \\
\hline 4 & Cocoa & 2 & 198 & 27 & 13.6 & 16 & 8.1 & 5 & 2.5 \\
\hline 5 & Coffee & 4 & 396 & 57 & 14.4 & 23 & 5.8 & 12 & 3.0 \\
\hline 6 & Cowpea & 7 & 693 & 107 & 15.4 & 28 & 4.0 & 32 & 4.6 \\
\hline 7 & Egusi seeds & 7 & 693 & 103 & 14.9 & 24 & 3.5 & NA & NA \\
\hline 8 & Groundnuts & 8 & 792 & 84 & 10.6 & 20 & 2.5 & 17 & 2.1 \\
\hline 9 & Kidney beans & 10 & 990 & 171 & 17.3 & 31 & 3.1 & 54 & 5.5 \\
\hline 10 & Maize & 11 & 1089 & 176 & 16.2 & 31 & 2.8 & 31 & 2.8 \\
\hline 11 & Soybeans & 6 & 594 & 102 & 17.2 & 32 & 5.4 & 19 & 3.2 \\
\hline 12 & White pepper & 2 & 198 & 40 & 20.2 & 29 & 14.6 & 9 & 4.5 \\
\hline
\end{tabular}

NA: Not Applicable, because of no existing MRLs. 


\section{Discussion}

According to the European Commission, if the recoveries of pesticides are consistently high or low in replicate tests, this outcome is acceptable [26]. The method appeared to be suitable for detecting almost all the targeted compounds in all the food items, and adjustments were performed for recoveries lower than $70 \%$ or higher than $120 \%$. Consistently low recoveries were found with apolar compounds, in cleaned-up samples, and in samples with high fat content like groundnuts, Egusi seeds, and cocoa beans. This can be attributed to losses during the extraction and clean-up steps with d-SPE tubes in the modified QuEChERS method [27]. These observations agree with the findings of Mekonen et al. [2] on similar food items. Conversely, very high or very low recovery values were also consistently obtained for polar pesticides, and in some samples which did not require clean-up. In LC-MS/MS analysis, this may be due to the presence of matrix components that coelute with the compounds of interest and can interfere with the ionization process in the mass spectrometer, causing ionization suppression or enhancement; this phenomenon is called the matrix effect [28]. To further understand these recovery differences and ensure a thorough quantitative analysis, the matrix effect of these food matrices on the screened pesticides must be investigated.

In this study, pesticides were detected in all the samples. In a similar preliminary study of pesticide residues in fruits at the market level in Accra, Ghana, pesticide residues were also found in all the 320 samples of pawpaw, tomato, and apple [29]. All 42 samples of staple food items from the Jimma zone in Ethiopia also contained 1 or more pesticide [2]. Additionally, our results of the 62 quantified pesticides in the food items agree with the findings of Winter [30], who reported a total of 77 individual pesticides detected from market basket samples analyzed by the U.S. Food and Drug Administration in 2004 and 2005. The report of Manfo et al. [4], who showed that 56 pesticides containing 25 active substances were used by farmers of Djutitsa, located in our sampling region of Cameroon, can justify our results. Moreover, Mahob et al. [6] found that 35 different chemicals were marketed in Cameroon for use in cocoa, among which there were 4 herbicides, 11 fungicides, and 20 insecticides. The great majority of farmers $(96.8 \%)$ apply pesticides on their farms, while fungicides were used most often $(61.8 \%)$, followed by insecticides (38.2\%).

In a similar study on staple foods from Ethiopia, the main pesticides detected were DDT, endosulfan, cypermethrin, and permethrin at concentrations varying from 0.011 to $1.115 \mathrm{mg} / \mathrm{kg}$ [2]. In maize, cowpea, and millet samples from northern Cameroon, organochlorine and organophosphorus pesticides including $\beta$-endosulfan, lindane, pirimiphos-methyl, and malathion were detected more frequently [10]. Moreover, Sonchieu et al. [5] found that in cowpea samples from the markets of Ngaoundéré in northern Cameroon, residues of the organophosphorus pesticides dichlorvos, methyl-parathion, malathion, profenofos, diazinon, and chlorpyrifos were found in concentrations ranging from 0.02 to $5.4 \mathrm{mg} / \mathrm{kg}$. The above results corroborate our findings of halogenated compounds as the most distributed pesticides in samples from the western highlands of Cameroon, and the pesticide concentrations we obtained are on par with all these studies.

Our analyses revealed that $34.4 \%$ of the pesticides were found above their existing MRL values and in $38 \%$ of the positive analyses. Our results are comparable to the findings of Bempah and Donkor [29], who reported 32.8\% of fruit samples with residues above MRLs, and Mekonen et al. [2], in which one-third of samples were above the MRLs. However, Sonchieu et al. [10] obtained higher values, with $75 \%$ of samples containing pesticide residues above MRLs. These disparities could be due to the single food item (cowpea) used in their study.

We found 12 banned compounds in the samples, including DTT and its metabolites, as well as $\beta$-Hexachlorocyclohexane, a by-product of lindane. Similar results were reported in Ghana [29], in Ethiopia [2], and in samples from northern Cameroon [5,10,17]. This raises the concern of the presence of banned pesticides in foods in Africa, and particularly in Cameroon. This can result from environmental persistence of these pesticides, which could have returned into the food chain. However, in Cameroon, the availability of a huge stock of obsolete pesticides, coupled with their illegal use in agriculture, can justify the high distribution and concentration of banned pesticides in analyzed food 
samples. In 353 stores visited in the whole country, Tarla et al. [16] inventoried 210,047 kg and 309,521 L of obsolete pesticides, among which there was $4146 \mathrm{~kg}$ of persistent organic pollutants. Eight officially banned active ingredients were still being used in Cameroonian cocoa farms, and over $77 \%$ of farmers did not respect the official spray recommendations for chemicals [6]. Similarly, in Foumbot, one of our sampling locations, it was found that because of the absence of any formal training on pesticide application, and the lack of assistance from agricultural extension agents, farmers did not respect treatment frequencies [7]. Moreover, Sonchieu et al. [17] reported that the presence of high residues in northern Cameroon samples indicates the continuous use of banned pesticides in Cameroon acquired from black markets, because of their effectiveness and low price, to the detriment of consumer health.

\section{Conclusions}

It is critical to understand the occurrence of agrochemical contaminants in foods for assessing the health risk and preserving consumer health. This study validated a multi-residue method, and used it to screen 99 pesticides in 12 agricultural products from the food basket of Cameroon using LC-MS/MS and GC-ECD. We found that samples from all 6 locations and of all 12 food items were contaminated with one or more of the 63 pesticides quantified, among which 12 banned compounds were found. Halogenated pesticides, especially malathion, were highly distributed among the samples. Chili pepper and white pepper were the most contaminated food items. Twenty one pesticides were found above their European Union MRL values and represented 38\% of the positive samples. These results pave the way for estimating the potential health risks associated with exposure to these pesticides in Cameroon. They also represent scientific evidence to create awareness on the necessity of good pesticide monitoring in Cameroon. There is an urgent need to develop strategies for lowering pesticide residues in food, and actions to be taken by regulatory authorities to manage the countries obsolete pesticide stock and regulate agrochemical usage in the country.

Supplementary Materials: The following are available online at http:/ /www.mdpi.com/2304-8158/7/11/184/s1; Table S1: Recovery data and validation parameters of analysis of 99 pesticides in 12 food items from western highlands of Cameroon by LC-MS/MS and GC-ECD; Table S2: Analysis of 99 pesticide residues in 72 samples of 12 agricultural products from western highlands of Cameroon by LC-MS/MS and GC-ECD.

Author Contributions: Conceptualization, J.H.Y.G., M.H., J.F.D., D.F. and P.S.; Data curation, J.H.Y.G. and M.H.; Formal analysis, J.H.Y.G., M.H. and A.W.; Funding acquisition, J.H.Y.G. and P.S.; Investigation, J.H.Y.G.; Methodology, J.H.Y.G., M.H. and P.S.; Project administration, P.S.; Resources, J.F.D., D.F. and P.S.; Supervision, P.S.; Validation, J.H.Y.G., M.H., A.W. and P.S.; Writing—original draft, J.H.Y.G.; Writing—review \& editing, J.H.Y.G., M.H., A.W., J.F.D. and D.F.

Funding: This research received no external funding.

Acknowledgments: The authors are thankful to the Erasmus Mundus Action 2 CARIBU Project for sponsoring and supporting the study. The great laboratory assistance of Lilian Goeteyn is gratefully acknowledged.

Conflicts of Interest: The authors declare no conflict of interest.

\section{References}

1. Wang, J.; Chow, W.; Leung, D. Applications of LC/ESI-MS/MS and UHPLC QqTOF MS for the determination of 148 pesticides in fruits and vegetables. Anal. Bioanal. Chem. 2010, 396, 1513-1538. [CrossRef] [PubMed]

2. Mekonen, S.; Ambelu, A.; Spanoghe, P. Pesticide residue evaluation in major staple food items of Ethiopia using the QuEChERS method: A case study from the Jimma zone. Environ. Toxicol. Chem. 2014, 33, 1294-1302. [CrossRef] [PubMed]

3. Matthews, G.; Wiles, T.; Baleguel, P. A survey of pesticide application in Cameroon. Crop Prot. 2003, 22, 707-714. [CrossRef]

4. Manfo, F.P.T.; Moundipa, P.F.; Déchaud, H.; Tchana, A.N.; Nantia, E.A.; Zabot, M.-T.; Pugeat, M. Effect of agropesticides use on male reproductive function: A study on farmers in Djutitsa (Cameroon). Environ. Toxicol. 2012, 27, 423-432. [CrossRef] [PubMed] 
5. Sonchieu, J.; Ngassoum, M.B.; Tchatchueng, J.B.; Srivastava, A.K.; Srivastava, L.P. Contamination of cowpea and by-products by organophosphorous pesticide residues in Ngaoundere markets: Dietary risk estimation and degradation study. Afr. J. Food Sci. 2013, 7, 92-102. [CrossRef]

6. Mahob, R.J.; Hoopen, G.M.T.E.N.; Dibog, L.; Nyassé, S.; Rutherford, M.; Mbenoun, M.; Babin, R.; Amang, J.A.; Bilong, C.F.B. Pesticides use in cocoa sector in Cameroon: Characterization of supply source, nature of actives ingredients, fashion and reasons for their utilization. Int. J. Biol. Chem. Sci. 2014, 8, 1976-1989. [CrossRef]

7. Tarla, D.; Manu, I.N.; Tamedjouong, Z.T.; Kamga, A.; Fontem, D.A. Plight of Pesticide Applicators in Cameroon: Case of Tomato (Lycopersicon esculentum Mill.) Farmers in Foumbot. J. Agric. Environ. Sci. 2015, 4, 87-98. [CrossRef]

8. Price, C. Implications of pesticide residues in inter-rated ditchduke farming. Cent. Thail. Aquic. News 2008, 32, 23.

9. Gimou, M.-M.; Charrondiere, U.R.; Leblanc, J.-C.; Pouillot, R. Dietary exposure to pesticide residues in Yaoundé: The Cameroonian total diet study. Food Addit. Contam. Part A 2008, 25, 458-471. [CrossRef] [PubMed]

10. Sonchieu, J.; Benoit Ngassoum, M.; Bosco Tchatchueng, J.; Srivastava, A.K.; Srivastava, L.P. Survey of pesticide residues in maize, cowpea and millet from northern Cameroon: Part I. Food Addit. Contam. Part B 2010, 3, 178-184. [CrossRef] [PubMed]

11. Gama, E.N.; Folorunso, S.T.; Adeola, S.S. Analysis of factors affecting the technical efficiency of cocoa producers in the south-west region of Cameroon. J. Agric. Res. Dev. 2016, 14, 89. [CrossRef]

12. Nchare, A. Analysis of Factors Affecting the Technical Efficiency of Arabica Coffee Producers in Cameroon. AERC Research Paper 163, Nairobi. Available online: https:/ /opendocs.ids.ac.uk/opendocs/bitstream/ handle/123456789/2675/RP\%20163.pdf?sequence=1\&isAllowed=y (accessed on 16 June 2018).

13. Tayoh, L.N.; Kiyo, M.L.I.; Nkemnyi, M.F. Chemical fertilizer application and farmers perception on food safety in Buea, Cameroon. Agric. Sci. Res. J. 2016, 6, 287-295.

14. European Food Safety Authority (EFSA). Combined review of the existing maximum residue levels (MRLs) for the active substances metalaxyl and metalaxyl-M. EFSA J. 2015, 13, 4076. [CrossRef]

15. MINADER. Décision No. 01326/16/D/MINADER/SG/DRCQ/SDRP/SRP Portant Interdiction de L'importation et de L'homologation des Formulations de Pesticide à Base de Métalaxyl au Cameroun; Ministère de l'Agriculture et du Développement Rural (MINADER): Yaounde, Cameroon, 2016.

16. Tarla, D.N.; Tchamba, N.M.; Baleguel, N.P.; Fontem, D.A.; Baleguel, P.D.; Hans, D. Inventory of obsolete pesticide stockpiles in Cameroon. Sch. J. Agric. Sci. 2014, 4, 43-50.

17. Sonchieu, J.; Srivastava, A.K.; Ngassoum, B.M.; Tchatchueng, J.B.; Srivastava, L.P. Contamination of cowpea (Vignaunguiculata (L.)Walp) and derived products by residues of banned pesticides in Cameroon: Health risk estimation. J. Pestic. 2017, 104, 147-160.

18. Institut National de la Statistique du Cameroun. Agriculture. In Annuaire Statistique du Cameroun; Institut National de la Statistique: Yaounde, Cameroon, 2015; pp. 232-255.

19. Anastassiades, M.; Lehotay, S.J.; Štajnbaher, D.; Schenck, F.J. Fast and easy multiresidue method employing acetonitrile extraction/partitioning and "dispersive solid-phase extraction" for the determination of pesticide residues in produce. J. AOAC Int. 2003, 86, 412-431. [PubMed]

20. Lehotay, S.J.; De Kok, A.; Hiemstra, M.; Van Bodegraven, P. Validation of a fast and easy method for the determination of residues from 229 pesticides in fruits and vegetables using gas and liquid chromatography and mass spectrometric detection. J. AOAC Int. 2005, 88, 595-614. [PubMed]

21. Wilkowska, A.; Biziuk, M. Determination of pesticide residues in food matrices using the quechers methodology. Food Chem. 2011, 125, 803-812. [CrossRef]

22. Wumbei, A.; Senaeve, D.; Houbraken, M.; Spanoghe, P. Pesticides residue analysis in yam from selected markets across Ghana and Belgium: An evaluation of the QUECHERS method. Int. J. Food Contam. 2018, 5, 1-10. [CrossRef]

23. MINADER. Liste des Pesticides homologués au Cameroun au 31 Juillet 2013. Liste Réservée au Grand Public. Commission Nationale D'HOMOLOGATION des Pesticides à Usage Agricole; Ministère de l'Agriculture et du Développement Rural (MINADER): Yaounde, Cameroon, 2013; p. 44. (In French)

24. Houbraken, M.; Spranghers, T.; De Clercq, P.; Cooreman-Algoed, M.; Couchement, T.; De Clercq, G.; Verbeke, S.; Spanoghe, P. Pesticide contamination of Tenebrio molitor (Coleoptera: Tenebrionidae) for human consumption. Food Chem. 2016, 201, 264-269. [CrossRef] [PubMed] 
25. Amulen, D.R.; Spanoghe, P.; Houbraken, M.; Tamale, A.; de Graaf, D.C.; Cross, P.; Smagghe, G. Environmental contaminants of honeybee products in Uganda detected using LC-MS/MS and GC-ECD. PLoS ONE 2017, 12, e0178546. [CrossRef] [PubMed]

26. European Commission Guidance Document on Analytical Quality Control and Method Validation Procedures for Pesticides Residues Analysis in Food and Feed. Available online: https:/ / ec.europa.eu/food/ sites/food/files/plant/docs/pesticides_mrl_guidelines_wrkdoc_2017-11813.pdf (accessed on 12 June 2018).

27. Pizzutti, I.R.; de Kok, A.; Dickow Cardoso, C.; Reichert, B.; de Kroon, M.; Wind, W.; Weber Righi, L.; Caiel da Silva, R. A multi-residue method for pesticides analysis in green coffee beans using gas chromatography-negative chemical ionization mass spectrometry in selective ion monitoring mode. J. Chromatogr. A 2012, 1251, 16-26. [CrossRef] [PubMed]

28. Van Eeckhaut, A.; Lanckmans, K.; Sarre, S.; Smolders, I.; Michotte, Y. Validation of bioanalytical LC-MS/MS assays: Evaluation of matrix effects. J. Chromatogr. B 2009, 877, 2198-2207. [CrossRef] [PubMed]

29. Bempah, C.K.; Donkor, A.K. Pesticide residues in fruits at the market level in Accra Metropolis, Ghana, a preliminary study. Environ. Monit. Assess. 2011, 175, 551-561. [CrossRef] [PubMed]

30. Winter, C.K. Chronic dietary exposure to pesticide residues in the United States. Int. J. Food Contam. 2015, 2, 11. [CrossRef]

(C) 2018 by the authors. Licensee MDPI, Basel, Switzerland. This article is an open access article distributed under the terms and conditions of the Creative Commons Attribution (CC BY) license (http:/ / creativecommons.org/licenses/by/4.0/). 